\title{
Balbiani Body
}

National Cancer Institute

\section{Source}

National Cancer Institute. Balbiani Body. NCI Thesaurus. Code C32181.

A collection of mitochondria, germinal plasm and fragments of both the endoplasmic reticulum and Golgi that is found next to the nucleus during early stages of oocyte development. 